\title{
Creating a Strategic Partnership for Educating Nurse Practitioner Students about Sexual Health
}

\author{
Stefan Rowniak \\ School of Nursing and Health Professions, University of San Francisco, San Francisco, CA, USA \\ Email: srrowniak@usfca.edu
}

Received 8 July 2014; revised 9 August 2014; accepted 17 August 2014

Copyright (C) 2014 by author and Scientific Research Publishing Inc.

This work is licensed under the Creative Commons Attribution International License (CC BY). http://creativecommons.org/licenses/by/4.0/

cC) (i) Open Access

\begin{abstract}
Sexual health is an essential and often neglected component of primary care. Nurse practitioners are ideal members of the healthcare team to be providing sexual health information, diagnoses, and treatments. Unfortunately, this is an area that has been lacking in the education of all healthcare providers. This paper describes a program that incorporates sexual health into the curriculum for nurse practitioner students through collaboration between the university school of nursing and the local health department. Given the increasing shortage of clinical sites and the need to train nurse practitioners to be competent in the delivery of sexual health, this is a model that could benefit other schools of nursing.
\end{abstract}

Keywords

Nursing Education, Nurse Practitioners, Sexual Health, Sexual Education

\section{Introduction}

Sexual health has been acknowledged to be an important and often overlooked aspect of healthcare (Dean \& Fenton, 2010; Institute of Medicine, 2011; Steiner, Aquino, \& Fenton, 2013; Swartzendruber \& Zenilman, 2010). According to the World Health Organization, sexual health encompasses the physical, psychological, emotional, and social aspects of sexuality and is not simply the absence of disease but requires an affirming approach to human sexual behavior and relationships, one that respects and protects the sexual rights of all individuals (World Health Organization). In the United States sexual health services tend to be offered, like much healthcare, in a fragmented manner and the outcomes have not been encouraging. HIV incidence has remained stable, instead of decreasing, and sexually transmitted diseases (STDs) and unintended pregnancy rates are among the 
worst in the developed world (Swartzendruber \& Zenilman, 2010). There is a tremendous need to institute a national strategy for sexual health in the United States and one important aspect of that is to incorporate sexual health services into primary care (Swartzendruber \& Zenilman, 2010). However, in order to accomplish this there is a need to improve the sexual health abilities of all healthcare personnel (Institute of Medicine, 2011). The focus of this paper is on nurse practitioners (NPs) and the role they can play in the provision of sexual health.

The need to improve skills in the area of sexual health is severely hampered by several convergent crises in the realm of nursing education. There is a dire shortage of both nurses and nursing educators combined with a dearth of clinical sites and the preceptors that are necessary to provide students with the skills and education they will need to graduate and practice effectively within the community (Burns et al., 2011; Lyon \& Peach, 2001; McNelis, Fonacier, McDonald, \& Ironside, 2011).

This paper will report on a successful method of incorporating sexual health training for nurse practitioner (NP) students in a university doctor of nursing practice (DNP) program utilizing collaboration between the academic institution and the local health department.

\section{The Need for a Sexual Health Focus}

The impetus for NP students to be educated and proficient in sexual health is the result of my own experience. Prior to becoming a professor at a local university in San Francisco I was a nurse practitioner at the San Francisco Department of Public Health STD clinic, City Clinic, for 20 years. It was in this capacity where I was able to observe how important sexual health was for overall patient health. It was also evident that this was an essential aspect of healthcare that, for even those patients who had a source of primary care, was quite often lacking or insufficient.

Sexual health is important for all patients but it is also a matter of public health and is best seen through the lens of the risks and needs of specific vulnerable populations (Dean \& Fenton, 2010; Steiner et al., 2013; Swartzendruber \& Zenilman, 2010). In San Francisco and the majority of urban centers in the United States, a disproportionate burden of HIV and STDs is within the gay population (Scheer et al., 2008). In fact, HIV has been described as "hyperendemic" among gay men in San Francisco (Scheer et al., 2008). Also adversely affected is the transgender population, especially transwomen (Herbst et al., 2008). A report published in the American Journal of Public Health (Mayer et al., 2008) suggests several reasons for healthcare disparities among lesbian, gay, bisexual, and transgender (LGBT) individuals. These include; 1) a reluctance to disclose sexual orientation or gender identity when seeking care, 2) lack of providers who are competent and comfortable discussing issues related to LGBT health, 3) being less likely to have health insurance and experience a wide variety of health disparities when compared to a heterosexual population, and 4) a lack of culturally appropriate prevention/education services (Kates \& Ranji, 2014; Ranji, Beamesderfer, Kates, \& Salganicoff, 2014).

Other populations at risk include all sexually active adolescents, persons with a current STD or an STD within the previous year, adults with multiple partners, and adults who are not consistent in condom use. African Americans are disproportionately affected by HIV and STDs, especially young African American men who have sex with men (U.S. Preventive Services Task Force, 2014).

The author's experience with patients at the clinic is that many who are at highest risk for HIV and STDs have not reported their sexual orientation and behavior to their primary care providers. This is sometimes due to patient reluctance to bring up the topic because of the concerns about stigma and possible adverse consequences regarding their medical care. It may also be due to discomfort or lack of the necessary skills on the part of the provider to even ask the appropriate questions. Likewise, the nursing profession and nursing academia have been reported to be in need of improving their skills in working with LGBT populations (Dorsen, 2012; Eliason, Dibble, \& Dejoseph, 2010; Keepnews, 2011). This means that doctors and nurses, the primary healthcare providers, are often missing the ideal opportunities to impact the sexual health of their patients. For some, this can be a chance to prevent infection with an STD or HIV. These missed opportunities have also been implicated in the slow uptake of the human papilloma virus (HPV) vaccine among those who could most benefit from it. Clinicians who do not feel competent or comfortable discussing sexual matters often find it difficult to bring up the importance of the HPV vaccine and it is, therefore, neither discussed nor provided (Centers for Disease Control and Prevention, 2013; Quinn, Vadaparampil, Johns, Alexander, \& Giuliano, 2014).

Sometimes the relationship that exists between the provider and the patient can result in a barrier to optimum care with regard to sexual health. For example, I had the experience of caring for a patient who was a religious 
leader in the local community. His position required celibacy, yet, as I have seen repeatedly, like most human beings he had sexual needs that sometimes manifested themselves in ways that resulted in unintended risks causing him much anxiety. He needed knowledgeable and compassionate care. Unfortunately, his primary care provider was also a member of his congregation. This made any honest and open discussion of sexual issues impossible, despite any promises of confidentiality. A similar situation exists for adolescent girls who need information and provision of birth control but their primary care provider is also the provider for their parents, who may not know or approve of them having sex. It is for these very reasons that specialty clinics like Planned Parenthood or health department STD clinics exist. However, for the majority of circumstances healthcare providers will be presented with, sexual health can and should be incorporated into a primary care setting.

\section{Nurse Practitioners as the Ideal Providers of Sexual Health}

The provision of sexual health is an ideal role for the nurse practitioner. This is an area of healthcare that does not demand an extensive medical knowledge of complex physiological processes and even more complex treatments. The basic knowledge can be easily provided within an NP education program. What is essential is the patient-centered ability to communicate sensitively and effectively with a wide variety of individuals about sexual matters in an honest matter-of-fact manner. It is also necessary to be able to competently provide these services to patients who are members of sexual and gender minority populations, many of whom have faced stigmatization within healthcare settings as well as the larger society. These are skills that are at the foundation of the nursing profession and NP students with adequate education and guided exposure can easily be trained to fill the role of expert sexual health providers.

NPs can conduct a sexual history followed by the appropriate physical examination. They are trained to provide prevention education, screening, diagnosing, and treatment. As clinicians who already have worked as nurses, they have experience in providing their care in a patient-centered manner. Instead of seeing NPs merely in a role of physician extenders, we in the university program believe that NPs are experts in the area of prevention/education.

\section{Collaboration between the University and the Department of Public Health}

The San Francisco Department of Public Health STD Clinic, City Clinic, is an ideal location to serve as a site for NP students to learn the essentials of sexual health. That includes taking a sexual history, performing a focused exam, collecting the appropriate specimens, making the diagnosis, and prescribing treatment. Also includes providing counseling that incorporates prevention/education that is honest and non-judgmental. The clinic sees a wide variety of individuals who range from being the "worried well" with very little real risk to those who are the absolute highest risk for STDs and HIV. In 2012 26.2\% of the patient visits were female, 40.1\% gay men, and $33.6 \%$ heterosexual men. Caucasians accounted for $46.5 \%$ of patient visits, Hispanics 21.5\%, African American 17.1\% and Asian/Pacific Islanders 13.3\% (San Francisco City Clinic, 2014). The clinic also sees a number of transgender patients, both transmen and transwomen. The diversity is great and it is essential that all clinicians working at the clinic possess the cultural competency to effectively work with their patients. It is also an ideal clinic to develop those skills necessary to work with populations of great diversity with regard to ethnicity, sexual orientation, and gender identity.

This clinical opportunity is possible because I am both professor at the university and I also hold a position at the clinic thus enabling the students to be taught by an experienced clinician in the area of sexual health. Often, in NP programs, a preceptor is located at a specific clinic and one or two students at a maximum might be able to be precepted at the clinic each semester. Also, the information learned at the clinical site may be very different from what was taught in the classroom. Utilizing a clinician preceptor who also lectures in the classroom helps ensure that the students are receiving consistency in the education and experience they need to provide them with a working knowledge of sexual health and how it applies to various patient populations.

This arrangement was reached through a series of discussions with the medical director of the clinic, representing the health department, and the dean of the school of nursing, representing the university. It was decided that the best approach would be to grant me two units of teaching credit for the semester for taking the students individually to the clinic for their day of immersion in sexual health. The day each week that I am with a student I am not paid by the clinic because of the compensation in units provided by the university. This mutually beneficial situation means that I am present to see patients but not included in the budgeted number of clinicians for 
that day. It therefore frees me from the time constraints that often pressure clinicians to be as efficient as possible by seeing the maximum number of patients. This prevents the role conflict that can occur when preceptors find the task of training NPs burdensome due workplace-generated pressures to prioritize patient care over student learning (Lyon \& Peach, 2001). This enables the time to be spent on providing patient care in a way that also optimizes student learning of demonstrated skills and assessments and through in-depth discussions of each case seen.

\section{Training the Students}

The program of training our NPs to provide competent sexual health is delivered in four steps; 1) providing the knowledge base, 2) developing the skills (both in the classroom setting), 3) observing and working with the patient, and 4) in-depth case discussion (both in the clinical setting).

The provision of knowledge regarding sexual health begins in the Health Assessment class. Each week is devoted to a specific system for assessment. Midway into the semester one of the week's readings and lecture pertain to sexual health. This includes developing competence in speaking to populations at risk for STDs and HIV such as gay men and transwomen, populations with which most of the students have a limited familiarity. Activities include watching several online videos that have been made to help healthcare providers work more effectively with sexual minorities. In class, lecture and discussion cover taking a sexual history, an epidemiological update of STDs, and how to diagnose and treat various STDs. Other aspects of sexual health such as reproductive health, prescribing various methods of birth control, and gynecological problems, are covered in subsequent lectures.

The skills are introduced and practiced first within the classroom and then applied at the clinic. Then each student has a one-on-one day at the STD clinic. This begins with microscopy in the morning that includes learning how to prepare and interpret gram stains with the emphasis on those organisms needed for the diagnosing of gonorrhea and non-gonococcal urethritis. They also learn how to obtain and interpret wet mounts, spun urine, and use of the darkfield microscope for the diagnosing of syphilis. Our university does not have microscopes on campus so this collaboration with the health department enables the students to learn microscopy skills without requiring the university to make a major purchase of very expensive equipment that will be used infrequently.

In the afternoon the students see patients with me. The clinic has drop-in hours at that time so a wide variety of patients seek services. I choose to see those patients who offer a good learning experience and all are asked if they object to being seen with a student NP. The vast majority of patients have no objections whatsoever. The students are instructed to observe the skills of taking the history, doing the physical exam, specimen collection, diagnosing, treatment, including partner delivered therapy (PDT), and counseling messages, including follow-up. When they feel comfortable, they are encouraged to take charge of the visit with my observation and assistance.

After each patient is seen, time is devoted to an in-depth discussion of all aspects of the case. This focuses on the risk for HIV and other STDs, prevention education, treatment and partner notification and/or partner delivered therapy (PDT), post-exposure prophylaxis (PEP), pre-exposure prophylaxis (PrEP) considerations, followup needs, primary care needs, vaccinations such as hepatitis A and B and HPV. Although the type of patients and diseases seen on any given day can never be predicted, all of the students state that have had a rich and rewarding experience usually involving discussions the likes of which they have never had with patients before. Some students will find that they are drawn to this kind of patient care and will request a clinical rotation of several weeks at the clinic for a thorough training in sexual health.

\section{Conclusion}

Given the shortage of nursing faculty and the dwindling number of available clinical sites for nursing students, new models are necessary to continue training nurses and nurse practitioners for meeting the increasing demands for primary care. As clinical sites are harder to find, it will be incumbent upon schools of nursing to devise new models for preceptor ship and locating appropriate clinical sites. The model presented demonstrates a partnership between a university school of nursing and the local health department, which can be beneficial for the university, the clinic, and ultimately for NP education, and the health of their future patients.

NP students have embraced this program enthusiastically. However it is faculty and nursing academia that need to understand the importance of providing NP students with adequate training in the sexual health needs of patients and the communities. It is essential to weave sexual health throughout the primary care curriculum. 
Sexuality and sexual health are not just concerns of our patients at fixed points in their lives but are relevant across the lifespan. As nurse educators it is our responsibility to improve nursing and NP education to fully incorporate this often-neglected aspect of healthcare

\section{References}

Burns, P., Williams, S. H., Ard, N., Enright, C., Poster, E., \& Ransom, S. A. (2011). Academic Partnerships to Increase Nursing Education Capacity: Centralized Faculty Resource and Clinical Placement Centers. Journal of Professional Nursing, 27, e14-e19. http://dx.doi.org/10.1016/j.profnurs.2011.07.004

Centers for Disease Control and Prevention (CDC) (2013). National and State Vaccination Coverage among Adolescents Aged 13 - 17 Years-United States, 2012. http://www.cdc.gov/mmwr/preview/mmwrhtml/mm6234a1.htm

Dean, H. D., \& Fenton, K. A. (2010). Addressing Social Determinants of Health in the Prevention and Control of HIV/AIDS, Viral Hepatitis, Sexually Transmitted Infections, and Tuberculosis. Public Health Reports, 125, 1-5.

Dorsen, C. (2012). An Integrative Review of Nurse Attitudes towards Lesbian, Gay, Bisexual, and Transgender Patients. Canadian Journal of Nursing Research, 44, 18-43.

Eliason, M. J., Dibble, S., \& Dejoseph, J. (2010). Nursing’s Silence on Lesbian, Gay, Bisexual, and Transgender Issues: The Need for Emancipatory Efforts. Advances in Nursing Science, 33, 206-218. http://dx.doi.org/10.1097/ANS.0b013e3181e63e49

Herbst, J. H., Jacobs, E. D., Finlayson, T. J., McKleroy, V. S., Neumann, M. S., \& Crepaz, N. (2008). Estimating HIV Prevalence and Risk Behaviors of Transgender Persons in the United States: A Systematic Review. AIDS and Behavior, 12, 117. http://dx.doi.org/10.1007/s10461-007-9299-3

Institute of Medicine (2011). The Health of Lesbian, Gay, Bisexual, and Transgender People: Building a Foundation for Better Understanding. Washington, DC: Institute of Medicine.

Kates, J., \& Ranji, U. (2014). Health Care Access and Coverage for the Lesbian, Gay, Bisexual, and Transgender (LGBT) Community in the United States: Opportunities and Challenges in a New Era.

http://kff.org/disparities-policy/perspective/health-care-access-and-coverage-for-the-lesbian-gay-bisexual-and-transgender -lgbt-community-in-the-united-states-opportunities-and-challenges-in-a-new-era/

Keepnews, D. M. (2011). Lesbian, Gay, Bisexual, and Transgender Health Issues and Nursing: Moving toward an Agenda. Advances in Nursing Science, 34, 163-170. http://dx.doi.org/10.1097/ANS.0b013e31821cd61c

Lyon, D. E., \& Peach, J. (2001). Primary Care Providers' Views of Precepting Nurse Practitioner Students. Journal of the American Academy of Nurse Practitioners, 13, 237-240. http://dx.doi.org/10.1111/j.1745-7599.2001.tb00027.x

Mayer, K. H., Bradford, J. B., Makadon, H. J., Stall, R., Goldhammer, H., \& Landers, S. (2008). Sexual and Gender Minority Health: What We Know and What Needs to Be Done. American Journal of Public Health, 98, 989-995. http://dx.doi.org/10.2105/AJPH.2007.127811

McNelis, A. M., Fonacier, T., McDonald, J., \& Ironside, P. M. (2011). Optimizing Prelicensure Students' Learning in Clinical Settings: Addressing the Lack of Clinical Sites. Nursing Education Perspectives, 32, 64-65. http://dx.doi.org/10.5480/1536-5026-32.1.64

Quinn, G. P., Vadaparampil, S. T., Johns, T., Alexander, K. A., \& Giuliano, A. R. (2014). Adolescent Sexual Activity and Cancer Risk: Physicians’ Duty to Inform? Current Medical Research and Opinion, 1-17. http://dx.doi.org/10.1185/03007995.2014.924913

Ranji, U., Beamesderfer, A., Kates, J., \& Salganicoff, A. (2014). Health and Access to Care and Coverage for Lesbian, Gay, Bisexual, and Transgender Individuals in the U.S. http://kff.org/disparities-policy/issue-brief/health-and-access-to-care-and-coverage-for-lesbian-gay-bisexual-and-transgend er-individuals-in-the-u-s/

San Francisco City Clinic (2014). San Francisco City Clinic. http://www.sfcityclinic.org/providers/\#Update2012

Scheer, S., Kellogg, T., Klausner, J. D., Schwarcz, S., Colfax, G., Bernstein, K., \& McFarland, W. (2008). HIV Is Hyperendemic among Men Who Have Sex with Men in San Francisco: 10-Year Trends in HIV Incidence, HIV Prevalence, Sexually Transmitted Infections and Sexual Risk Behaviour. Sexually Transmitted Infections, 84, 493-498. http://dx.doi.org/10.1136/sti.2008.031823

Steiner, R. J., Aquino, G., \& Fenton, K. A. (2013). Enhancing HIV/AIDS, Viral Hepatitis, Sexually Transmitted Disease, and Tuberculosis Prevention in the United States through Program Collaboration and Service Integration: The Case for Broader Implementation. Sexually Transmitted Diseases, 40, 663-668. http://dx.doi.org/10.1097/OLQ.0000000000000002

Swartzendruber, A., \& Zenilman, J. M. (2010). A National Strategy to Improve Sexual Health. Journal of the American Medical Association, 304, 1005-1006. http://dx.doi.org/10.1001/jama.2010.1252

U.S. Preventive Services Task Force (2014). Behavioral Counseling Interventions to Prevent Sexually Transmitted Infections: 
U.S. Preventive Services Task Force Recommendation Statement DRAFT. http://www.uspreventiveservicestaskforce.org/draftrec3.htm

World Health Organization. Gender and Human Rights.

http://www.who.int/reproductivehealth/topics/gender_rights/sexual_health/en/ 
Scientific Research Publishing (SCIRP) is one of the largest Open Access journal publishers. It is currently publishing more than 200 open access, online, peer-reviewed journals covering a wide range of academic disciplines. SCIRP serves the worldwide academic communities and contributes to the progress and application of science with its publication.

Other selected journals from SCIRP are listed as below. Submit your manuscript to us via either submit@scirp.org or Online Submission Portal.
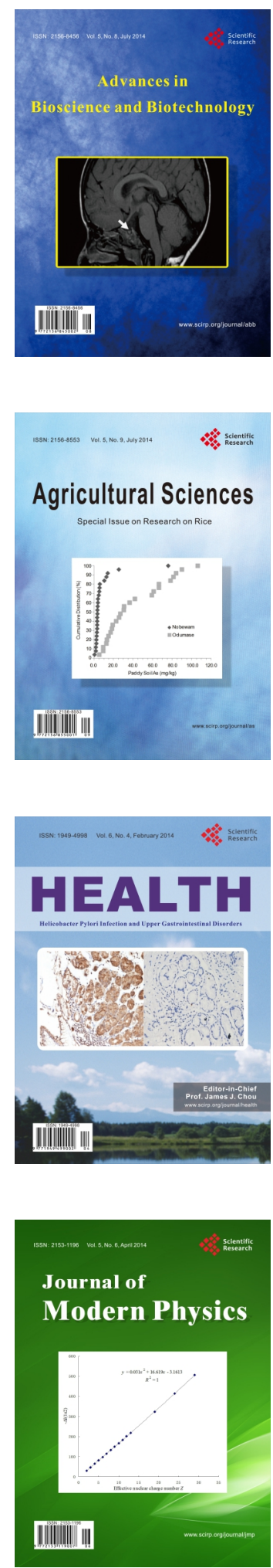
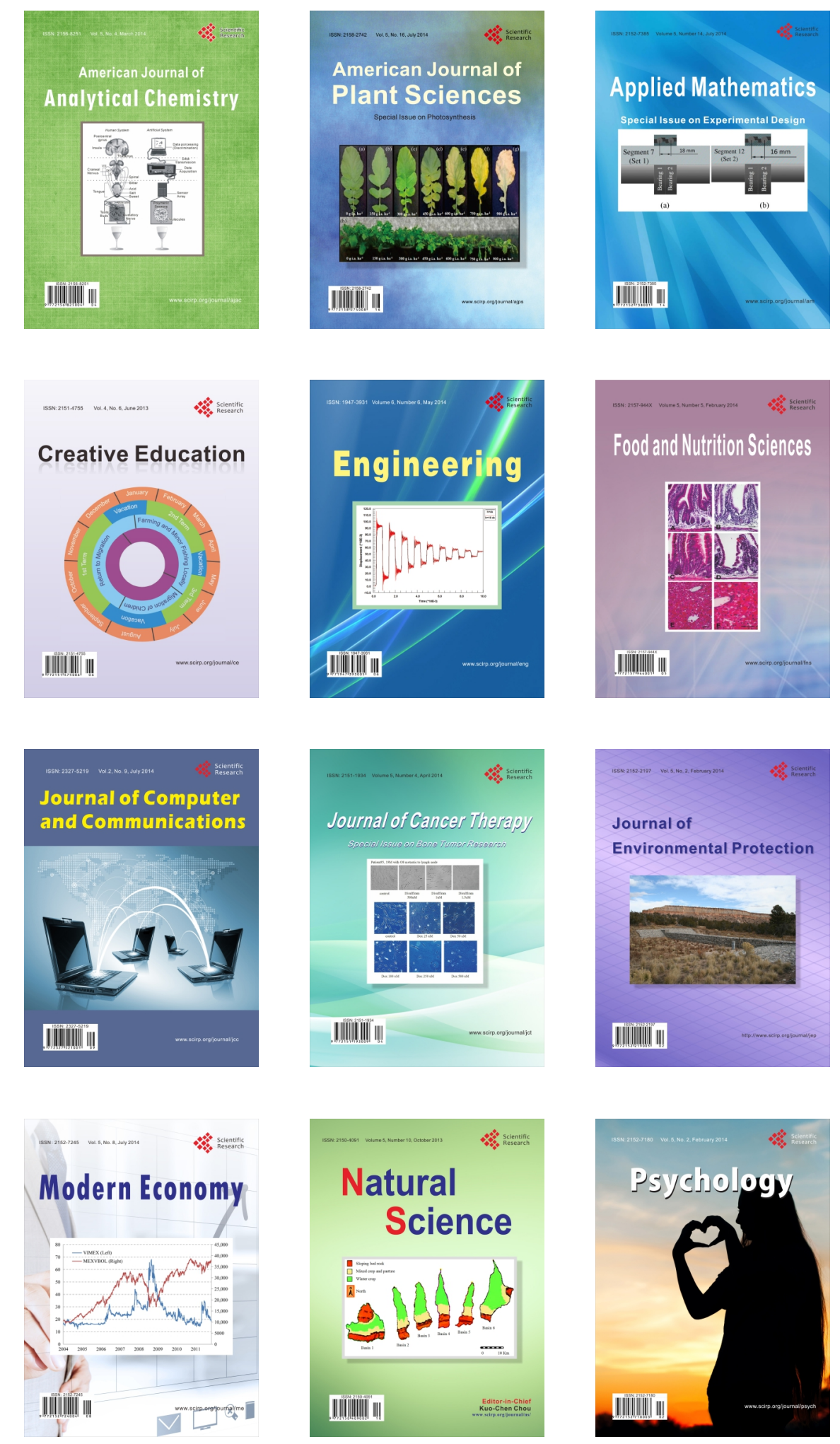